www.jmscr.igmpublication.org

Impact Factor 5.84

Index Copernicus Value: 83.27

ISSN (e)-2347-176x ISSN (p) 2455-0450

crossref DOI: _https://dx.doi.org/10.18535/jmscr/v5i5.148

Journal Of Medical Science And Clinical Research

\title{
Evaluation of Serum Creatine Kinase Muscle-Brain Fraction (CK-MB) and Lactate Dehydrogenase (LDH) as Markers of Perinatal Asphyxia in Term Neonates at Tertiary Health Care Centre in Bikaner
}

\author{
Authors \\ Dr Kuldeep Meena ${ }^{1 *}$, Dr R.K.Soni ${ }^{2}$, Dr Nishaat Ahmed ${ }^{3}$, Dr Nitesh ${ }^{4}$, Prerna Harsh ${ }^{5}$ \\ ${ }^{1,4}$ Resident, ${ }^{2}$ Professor, ${ }^{3}$ Assistant Professor, ${ }^{5}$ Msc Biochemistry Student \\ ${ }^{1-4}$ Department of Paediatrics, ${ }^{5}$ Department of Biochemistry \\ Sardar Patel Medical College, Bikaner, Rajasthan \\ Corresponding Author \\ Dr Kuldeep Meena \\ Resident, Department of Paediatrics, Sardar Patel Medical College, Bikaner, Rajasthan \\ Mobile no-7014852859, Email: meenakuldeep433@gmail.com
}

\begin{abstract}
Background: Perinatal asphyxia is a common neonatal problem and contributes significantly to neonatal morbidity and mortality. Globally, hypoxia of the newborn (birth asphyxia) or the fetus ("fresh stillbirth") is estimated to account for $23 \%$ of the 4 million neonatal deaths and $26 \%$ of the 3.2 million stillbirths each year.

Material and Methods: Prospective observational study. A study was conducted on 50 neonates comprising the cases and 50 neonates comprising the controls meeting the inclusion and exclusion criteria. The blood samples for $C K-M B$ and $L D H$ was drawn at $8 \pm 2$ and $72 \pm 2$ hours of age respectively and sent for analysis. A serum CK-MB value $>92.6$ U/L at 8 hours and LDH value $>580$ U/L at 72 hours was taken as the cut-off level.

Results: The cut-off $C K-M B$ value of $>92.6 \mathrm{U} / \mathrm{L}$ has $28 \%$ sensitivity with a specificity of $100 \%$. $C K-M B$ has a positive predictive value of $100 \%$ with a negative predictive value of $58.14 \%$. The cut-off LDH value of $>580$ U/L has $59.18 \%$ sensitivity with a specificity of $92 \%$. LDH has a positive predictive value of $87.88 \%$ with a negative predictive value of $69.70 \%$.

Conclusion: Estimation of CK-MB at 8 hours of life and LDH at 72 hours of life can help distinguish an asphyxiated from a no nasphyxiated term neonate in correlation with history and clinical features in the neonate.

Keywords: Perinatal asphyxia, Creatine kinase muscle-brain fraction (CK-MB), Lactate dehydrogenase (LDH), hypoxic ischemic encephalopathy (HIE).
\end{abstract}

\section{Introduction}

Globally, hypoxia of the newborn (birth asphyxia) or the fetus ("fresh stillbirth") is estimated to account for $23 \%$ of the 4 million neonatal deaths and $26 \%$ of the 3.2 million stillbirths each year ${ }^{1}$.
Data from National Neonatal Perinatal database (NNPD) suggests that perinatal asphyxia contributes to almost $20 \%$ of neonatal deaths in India $^{2}$. In India, $8.4 \%$ of inborn babies have a one minute Apgar score less than 7 and $1.4 \%$ suffer 
from hypoxic ischemic encephalopathy (HIE) ${ }^{2}$. Many different assessments attempt to predict fetal well-being during labour and following delivery. These include observing for the passage of meconium, electronic fetal heart rate monitoring via a cardiotocograph, Apgar score and the assessment of fetal acid-base balance. The signs of asphyxial injury are nonspecific and overlap with other illnesses. It is difficult to retrospectively diagnose perinatal asphyxia in the absence of perinatal records.

Transient myocardial ischemia (TMI) with myocardial dysfunction may occur in any neonate with a history of perinatal asphyxia. An elevated serum creatine kinase muscle-brain fraction (CKMB) fraction or cardiac troponin $\mathrm{T}$ (cTnT) level may be helpful in determining the presence of myocardial damage. An elevation of serum CKMB fraction of $>5 \%$ to $10 \%$ may indicate myocardial injury ${ }^{3}$. Leakage of intracellular enzymes such as alanine aminotransferase (ALT), aspartate aminotransferase (AST) and lactate dehydrogenase (LDH) signaling multi organ dysfunction is seen together with HIE after perinatal asphyxia ${ }^{4}$.

\section{Materials and Methods}

Study design: Hospital based prospective study.

Study duration: 12 months

Study place: Neonatal Intensive Care Unit (NICU) and Post natal wards of PBM Hospital, Bikaner.

Study population: asphyxiated and nonasphyxiated term neonates recruited from Neonatal Intensive Care Unit (NICU) and Post natal wards of PBM Hospital, Bikaner.

Sample size: 50 Cases and Controls comprised of asphyxiated and non-asphyxiated neonates, respectively.

The case group: It included 50 neonates fulfill the inclusive criteria

\section{Inclusion Criteria:}

1. Gestational age $\geq 37$ weeks.

2. Appropriate for gestational age.
3. The neonates will be identified to have experienced perinatal asphyxia when at least 3 of the following are present:

a) Intrapartum signs of fetal distress, as indicated by non reassuring NST on continuous electronic fetal monitoring and/ or by thick meconium staining of the amniotic fluid.

b) Apgar score of $<7$ at one minute of life.

c) Resuscitation with $>1$ minute of positive pressure ventilation before stable spontaneous respiration.

d) Profound metabolic or mixed acidemia $(\mathrm{pH}<7.00)$ in an umbilical artery blood sample, if obtained.

e) Mild, moderate or severe hypoxic ischemic encephalopathy (HIE), as defined by sarnat and sarnat 1976.

\section{Exclusion Criteria}

1) Congenital malformations.

2) Maternal drug addiction.

3) Neonates born to mothers who would have received magnesium sulphate within 4 hours prior to delivery or opiods (pharmacological depression).

4) Hemolytic disease of the newborn.

5) Neonates born to mothers consuming alcohol

6) Neonates born to mothers who are smokers

7) Neonates born to mothers on anti epileptics

The control group: It will include term apparently healthy neonates appropriate for gestational age without signs of peinatal asphyxia as evidenced by normal fetal heart rate patterns, clear liquor and one minute Apgar score $>7$.

\section{Method of Data Collection}

All neonates included in the study had the following done:

-Detailed maternal history, assessment of intrauterine fetal well being by continuous electronic fetal monitoring, meconium staining of amniotic fluid, birth events, Apgar score, sex of the baby and weight of the baby were recorded. Gestational 
age was assessed by New Ballard scoring system. Arterial blood gas analysis (ABG) was done if umbilical arterial blood was obtained.

-Thorough clinical and neurological examination was done for all the neonates included in the study.

-Blood samples were collected from the neonates and sent for:

A- Creatine Kinase Muscle-Brain fraction (CKMB) levels.

B- blood sugar.

C- Lactate Dehydrogenase (LDH) levels.

Blood for CK-MB was drawn at $8 \pm 2$ hours ${ }^{5}$. Blood for LDH was drawn at $72 \pm 2$ hours of age . The upper limit of the normal range of CK-MB at $5-8$ hours of life is $7.9 \%$ of $1,175 \mathrm{U} / \mathrm{L}$ which is 92.6 U/L taken as the cut-off level ${ }^{6}$.

The normal reference value of $\mathrm{LDH}$ in neonates and infants $<1$ year is $170-580 \mathrm{U} / \mathrm{L}^{6}$. A value $>580 \mathrm{U} / \mathrm{L}$ at 72 hours was taken as the cut-off level.

\section{Sample Collection}

Blood was collected each time from the peripheral venous site at $8 \pm 2$ hours for CK-MB and $72 \pm 2$ hours of age for $\mathrm{LDH}$ respectively under aseptic precautions. Serum CK-MB was analyzed by immunoassay on $1 \mathrm{~mL}$ clotted blood. Serum $\mathrm{LDH}$ was analyzed by the liqui UV test on $1 \mathrm{~mL}$ clotted blood.

\section{Data analysis}

Data will be recorded on a Performa. The data analysis will be computer based; SPSS-22 will be used for analysis. For categoric variables chisquare test will be used. For continuous variables independent samples's $t$-test will be used. $p$-value $<0.05$ will be considered as significant.

\section{Results}

This prospective study was conducted in NICU of Pediatrics PBM hospital Bikaner attached with S.P.M. college Bikaner. Cases and Controls comprised of asphyxiated and non-asphyxiated neonates, respectively. The blood samples from 50 neonates comprising the cases and 50 neonates comprising the controls constituted the material for the study. Among the 50 neonates in case group, there were $33(66 \%)$ males and $17(34 \%)$ females. Among the control group of 50 neonates, there were $28(56 \%)$ males and $22(44 \%)$ females. Gender distribution of neonates is statistically similar between two groups with $\mathrm{P}=0.591$. Among the 50 neonates in case group, $33(66 \%)$ neonates weighed between2.5-3.0 kg, 15 (30\%) weighed between $3.0-3.5 \mathrm{~kg}$ and $2(4 \%)$ weighed $>3.5 \mathrm{~kg}$. Among the control group of 50 neonates, 33 (66\%) neonates weighed between $2.5-3.0 \mathrm{~kg}, 15$ (30\%) weighed between $3.0-3.5 \mathrm{~kg}$ and $1(2 \%)$ weighed $>3.5 \mathrm{~kg}$. The mean weight in case group was $2.97 \pm 0.29 \mathrm{~kg}$ and in control group was $2.93 \pm 0.29 \mathrm{~kg}$. Birth weight distribution is statistically similar with $\mathrm{P}=0.485$. Among the 50 neonates in case group, $26(52 \%)$ were born to primi mothers and 24 (48\%) were born to multi gravida mothers. Among the control group of 50 neonates, $29(58 \%)$ were born to primi mothers and $21(42 \%)$ were born to multi gravida mothers. Proportion of primi and multi gravida mothers are statistically similar with $\mathrm{P}=0.130$.

Table: 1 Shows comparison of cut-off levels of CK-MB and LDH in cases and controls

\begin{tabular}{|c|c|c|c|}
\hline & Case & Control & P-Value \\
\hline $\begin{array}{l}\text { CK-MB } \\
\text { (cut-off } 92.6 \mathrm{U} / \mathrm{L} \text { ) }\end{array}$ & 50 & 50 & \\
\hline$<92.6 \mathrm{U} / \mathrm{L}$ & $30(60.0 \%)$ & $50(100.0 \%)$ & \multirow[b]{2}{*}{$<0.0001$} \\
\hline$>92.6 \mathrm{U} / \mathrm{L}$ & $20(40.0 \%)$ & 0 & \\
\hline $\begin{array}{l}\text { LDH } \\
\text { (cut-off 580U/L) }\end{array}$ & 50 & 50 & \multirow{3}{*}{$<0.0001$} \\
\hline$<580 \mathrm{U} / \mathrm{L}$ & $22(44 \%)$ & $49(98.0 \%)$ & \\
\hline$>580 \mathrm{U} / \mathrm{L}$ & $28(56 \%)$ & $1(2 \%)$ & \\
\hline
\end{tabular}


Among the 50 neonates in the case group, 30 (60\%) had CK-MB levels $<92.6 \mathrm{U} / \mathrm{L}$ and $20(40 \%)$ had CK-MB levels >92.6 U/L. None of the neonate in control group had CK-MB levels $>92.6$ U/L. All the $50(100 \%)$ neonates in the control group had CK-MB levels $<92.6 \mathrm{U} / \mathrm{L}$. The number of neonates with CK-MB levels >92.6 U/L is significantly $(\mathrm{P}<0.001)$. Among the 50 neonates in the case group, 22 (44\%) had LDH levels $<580 \mathrm{U} / \mathrm{L}$ and $28(56 \%)$ had LDH levels $>580$ U/L. Of the 50 neonates in control group 49 (98\%) had LDH levels <580 U/L and 1 (2\%) had LDH level $>580 \mathrm{U} / \mathrm{L}$. The number of neonates with $\mathrm{LDH}$ levels $>580 \mathrm{U} / \mathrm{L}$ is significantly more in cases when compared to controls with $\mathrm{P}<0.001$.

Table: 2. Shows comparison of CK-MB and LDH levels in cases and controls

\begin{tabular}{|l|c|c|c|}
\hline & Case & Controll & P-value \\
\hline $\begin{array}{l}\text { CK-MB(U/L) } \\
\text { (at } 8 \text { hours })\end{array}$ & & & \\
\hline mean \pm SD & $86.94 \pm 16.94$ & $47.42 \pm 6.53$ & $<0.001^{* *}$ \\
\hline $\begin{array}{l}\text { LDH(U/L) } \\
\text { (at } 72 \text { hours })\end{array}$ & & & \\
\hline mean \pm SD & $548 \pm 67.69$ & $372.6 \pm 67.69$ & $<0.001^{* *}$ \\
\hline
\end{tabular}

The mean CK-MB level at $8 \pm 2$ hours was $86.98 \pm 16.94 \mathrm{U} / \mathrm{L}$ in case group and $47.42 \pm 6.53$ $\mathrm{U} / \mathrm{L}$ in the control group. The mean value is significantly higher in cases compared to controls with $\mathrm{P}<0.001$. The mean $\mathrm{LDH}$ level at $72 \pm 2$ hours was $548 \pm 67.69 \mathrm{U} / \mathrm{L}$ in case group and $372.6 \pm 67.69 \mathrm{U} / \mathrm{L}$ in the control group. The mean value is significantly higher in cases compared to controls with $\mathrm{P}<0.001$.

Table: 3 Shows correlation of Apgar score, CK-MB and LDH with severity of HIE.

\begin{tabular}{|c|c|c|c|c|}
\hline \multirow[b]{2}{*}{ Variables } & \multicolumn{3}{|c|}{ HIE } & \multirow[b]{2}{*}{$\mathrm{P}$ value } \\
\hline & I & II & III & \\
\hline \multicolumn{5}{|l|}{ CK-MB(U/L) } \\
\hline$<92.6$ & $19(95 \%)$ & $6(50 \%)$ & $5(27.77 \%)$ & 0.0001 \\
\hline$>92.6$ & $1(5 \%)$ & $5(\%)$ & $13(72.22 \%)$ & \\
\hline \multicolumn{5}{|l|}{$\mathrm{LDH}(\mathrm{U} / \mathrm{L})$} \\
\hline$<580.0$ & $18(90 \%)$ & $3(25 \%)$ & $1(5.66 \%)$ & 0.0001 \\
\hline$>580$ & $2(10 \%)$ & $9(75 \%)$ & $17(94.44 \%)$ & \\
\hline Total & $20(100.0 \%)$ & $12(100.0 \%)$ & $18(100.0 \%)$ & \\
\hline
\end{tabular}

Among the 50 neonates in the case group, 30 (60\%) had CK-MB levels <92.6 U/L and 20 (28\%) had CK-MB levels >92.6 U/L. Out of the 50 neonates, 50 (100\%) developed HIE. 19 (95\%) case of HIE I, $6(50 \%)$ cases of HIE II and 5 $(27.77 \%)$ case of HIE III had CK-MB levels $<92.6 \mathrm{U} / \mathrm{L} .1(5 \%)$ cases of HIE I, $6(50 \%)$ cases of HIE II and $13(72.22 \%)$ cases with HIE III had CK-MB levels >92.6 U/L. The correlation of cut-off CK- MB level of $92.6 \mathrm{U} / \mathrm{L}$ with the severity of HIE is significant $(\mathrm{P}=0.0001)$. Out of the 50 neonates, $22(44 \%)$ had $\mathrm{LDH}$ levels $<580$ $\mathrm{U} / \mathrm{L}$ and $28(56 \%)$ had LDH levels $>580 \mathrm{U} / \mathrm{L}$. $50(100 \%)$ cases developed HIE. 18 (90\%) case of
HIE I, 3 (25\%) cases of HIE II and 1(5.55\%) case of HIE III had LDH levels <580 U/L. 2 (10\%) cases of HIE I, 9 (75\%) cases of HIE II and 17 (94.44\%) cases with HIE III had LDH levels $>580$ U/L. The correlation of cut-off LDH level of $580 \mathrm{U} / \mathrm{L}$ with the severity of HIE is significant $(\mathrm{P}=0.0001)$.

\section{Discussion}

Several studies have been conducted to evaluate better markers that help to differentiate asphyxial and nonasphyxial etiology in neonates. Primhak et $\mathrm{al}^{7}$ observed that the CK-MB in both normal $(n=43)$ and asphyxiated $(n=20)$ neonates, peaked 
at 8 hours and fell by 72 hours. Absolute and percentage CK-MB levels were higher in asphyxiated babies. Omokhodion SI et al ${ }^{8}$ studied the creatine kinase $(\mathrm{CK})$ and $\mathrm{CK}-\mathrm{MB}$ activities in 23 perinatally asphyxiated newborns and 12 healthy controls during the first $100 \mathrm{~h}$ of life. The asphyxiated infants had significantly elevated mean CK and absolute CK-MB but no fractional CK-MB activities.

The healthy controls, on the other hand, showed a steady decline in the activities of these enzymes from birth. Fonseca $\mathrm{E}$ et al ${ }^{9}$ found that antepartum fetal distress is associated with release of CK-BB, and particularly CK-MB; therefore, these biochemical markers may indicate either brain or myocardial damage. Barberi et al ${ }^{10}$ reported that CK, CK-MB, CK-MB/CK ratio and $\mathrm{LDH}$ were all increased in an asphyxiated group, while in a group with respiratory distress; only CK-MB and the CK-MB/CK ratio were abnormal.

The study by Karunatilaka DH et al ${ }^{11}$ also concluded that both the $\mathrm{CK}$ and $\mathrm{LDH}$ values are raised in birth asphyxia. LDH had $100 \%$ sensitivity, while CK-MB had $100 \%$ specificity for asphyxia in a study by Reddy $\mathrm{S}$ et al ${ }^{12}$.

Rajakumar PS et al ${ }^{13}$ observed that the cardiac enzymes, cTnT and CK-MB, were significantly elevated in cases when compared with controls. In 2010, Karlsson $\mathrm{M}$ et $\mathrm{al}^{14}$ in their clinical and experimental study done in 2008 on evaluation of organ damage in perinatal asphyxia concluded that in asphyxiated infants with differing degree of HIE and in infants where there had been signs of fetal distress during birth a cut off level of 1049 U/L for LDH was the most suitable predictor of mild, moderate, and severe HIE with a sensitivity of $100 \%$ and specificity of $97 \%$. This study shows that estimation of CK-MB at 8 hours of life and LDH at 72 hours of life can help distinguish an asphyxiated from a non-asphyxiated term neonate with reasonable degree of accuracy. LDH is having more diagnostic value than CKMB.

\section{Conclusion}

Estimation of CK-MB at 8 hours of life and LDH at 72 hours of life can help distinguish an asphyxiated from a nonasphyxiated term neonate in correlation with history and clinical features in the neonate.

Funding: No funding sources

Conflict of interest: None

Declared Ethical Approval: The study was approved by the Institutional Ethics Committee

\section{References}

1. Lawn JE, Cousens S, Zupan J. Lancet Neonatal Survival Steering Team. 4 million neonatal deaths: When? Where? Why? Lancet 2005; 365(9462): 891-900.

2. NNPD network. National Neonatal Perinatal Database- report for the year 2002-2003. NNF NNPD network. New Delhi: 2005. Availble from: http://www.newbornwhocc.org/pdf/ nnpd_report_2002-03.PDF.

3. Hansen AR, Soul JS. Perinatal Asphyxia and HypoxicIschaemic Encephalopathy. In: Cloherty JP, Eichenwald EC, Hansen AR, Stark AR, editors. Manual of neonatal care. 7th edition. Philadelphia: Lippincott Williams and Wilkins, a Wolters Kluwar business; 2012: 711-728.

4. Lackmann GM, Tollner U, Mader R. Serum enzyme activities in full-term asphyxiated and healthy newborns: enzyme kinetics during the first 144 hours of life. Enzyme \& Protein 1993; 47: 160172.

5. Levene MI. The asphyxiated newborn infant. In: Levene MI, Lilford RJ, editors. Fetal and neonatal neurology and neurosurgery. 2nd edition. Edinburgh: Churchil Livingstone 1995: 405-426.

6. Jedeikin R, Makela SK, Shennan AT, Rowe RD, Ellis G.. Creatine kinase isoenzymes in serum from cord blood and the blood of healthy full-term infants 
during the first three postnatal days. Clin Chem 1982; 28: 317- 322.

7. Primhak RA, Jedeikin R, Ellis G, Makela SK,Gillan JE, Swyer PR, et al. Myocardial ischaemia in asphyxia neonatorum. Electrocardiographic, enzymatic and histological correlations. Acta Pediatr Scand 1985; 74: 595-600.

8. Omokhodion SI, Losekoot TG, Jaiyesimi F. Serum creatine kinase and creatine kinase-MB isoenzyme activities in perinatally asphyxiated newborns.Eur Heart J. 1991; 12(9): 980-984.

9. Fonseca E, Garcia-Alonso A, Zarate A, Ochoa R, Galvan RE, Jimenez-Solis G. Elevation of activity of creatine phosphokinase (CK) and its isoenzymes in the newborn is associated with fetal asphyxia and risk at birth. Clin Biochem. 1995; 28(1): 91-5.

10. Barberi I, Calabro MP, Cordaro S, Gitto E, Sottile A, Prudente D, et al. Myocardial ischemia in neonates with perinatal asphyxia. Electrocardiographic, echocardiographic and enzymatic correlations. Eur J Pediatr 1999; 158: 742747.

11. Karunatilaka DH, Amaratunga GWDS, Perera KDNI, Caldera V. Serum creatine kinase and lactic dehydrogenase levels as useful markers of immediate and longterm outcome of perinatal asphyxia. Sri Lanka Journal of Child Health, 2000; 29: 49-52.

12. Reddy S, Dutta S, Narang A. Evaluation of Lactate Dehydrogenase, Creatine Kinase and Hepatic Enzymes for the Retrospective Diagnosis of Perinatal Asphyxia Among Sick Neonates. Indian Pediatrics 2008; 45: 144- 147.

13. Rajakumar PS,Vishnu Bhat B, Sridhar MG, Balachander J, Konar BC, Narayanan $\mathrm{P}$, et al. Cardiac Enzyme Levels in Myocardial Dysfunction in Newborns with
Perinatal Asphyxia. Indian Journal of Pediatrics 2008; 75: 1223- 1225.

14. Karlsson M, Wiberg-Itzel E, Chakkarapani E, Blennow M, Winbladh B, Thoresen M. Lactate dehydrogenase predicts hypoxic ischaemic encephalopathy in newborn infants: a preliminary study. Acta Paediatrica 2010; 99(8): 1139-1144. 